\title{
Independent Review Committee Member Curriculum Vitae
}

National Cancer Institute

\section{Source}

National Cancer Institute. Independent Review Committee Member Curriculum Vitae. NCI

Thesaurus. Code C125439.

A summary of the qualifications of independent review committee members, including educational and work experience. 